\title{
Antonio Smith (1832-1877): propuesta de catalogación de su obra
}

\section{Antonio Smith (1832-1877): a Proposal for Cataloging his Artwork}

\section{Lorena Villegas Medrano}

Facultad de Artes y Humanidades, Departamento de Artes, Universidad Católica de Temuco. Temuco, Chile.

Ivillegas@uct.cl

Samuel Quiroga Soto

Facultad de Artes y Humanidades, Departamento de Artes, Universidad Católica de Temuco. Temuco, Chile.

squiroga@uct.cl

\section{Resumen}

Smith en la búsqueda de una expresión personal se apartó de la jerarquía temática impuesta por la Academia de Pintura. Cultivó dos géneros preferentemente: el paisaje y la caricatura. Sin embargo, su figura ha sido escasamente estudiada, no existiendo un catastro de su obra. Por lo que proponemos catalogarla dentro del marco de la investigación "Antonio Smith, ¿Historia del paisaje en Chile?” La metodología empleada considera los aspectos formales de procedencia y publicaciones de las obras aplicando estándares implementados por el Centro de Documentación de Bienes Patrimoniales. Este trabajo busca generar información concisa, especializada y actualizada del legado de Smith.

Palabras clave: Antonio Smith, catalogación, caricatura, paisaje.

\section{Abstract}

Smith, an artist who in the search for a personal expression moved aside from the thematic hierarchy imposed by the Academy of Painting. Smith focused his work primarily on two genres: landscape and caricature. However, his works has been scarcely studied, with no record of his work. We propose under the study "Antonio Smith, History of the landscape en Chile?" To catalogue his work the methodology used considers formal aspects like origin y publications related to Smith's work, applying standards implemented by the Center of Documentation of Properties and Investments. This work seeks to generate specialized and concise information updating the legacy of Smith.

Keywords: Antonio Smith, Cataloguing, Caricature, Landscape. 


\section{Introducción}

$\mathrm{Al}$ intentar construir un relato que dé cuenta de la producción artística de Antonio Smith, nos encontramos con pocos registros de su obra. Lo escasamente disponible son apreciaciones de poco valor, en tanto información, pues no aportan datos de fichaje de la misma. Por ejemplo, Antonio Romera al referirse a La tarde, sólo entrega el nombre y el año de realización de la obra: 1875 . Sin embargo, se explaya en apreciaciones personales de poca importancia: "En La tarde, 1875, esa impresión subjetiva aparece en su plenitud. Smith no se ha limitado a dar plásticamente una realidad figurativa. Ha hecho algo más. Ha conseguido que lo inanimado e inerte adquiera un hondo sentido anímico. La ilusión de la realidad se acrecienta con la dimensión espiritual y con la circunstancia meteorológica" (Romera, Historia de la pintura chilena 36). De tal situación nace la necesidad de rastrear, en lo posible, toda la obra de Smith.

La catalogación permitirá la difusión y puesta en valor del legado del autor, poniendo a disposición datos que pueden ser muy útiles a otras investigaciones. La falta de información es una amenaza para la conservación de obras si no se toman los resguardos necesarios. Ya hemos tenido que lamentar la pérdida de 15 obras, entre las que se encontraba Valle cordillerano, de Smith, destruidas en un incendio que afectó a las dependencias del desaparecido Banco de Concepción (El Mercurio, 14 de enero de 1981). Otro ejemplo es el estado de "faltante", desde fines de 1973, de Sol de tarde en la montaña [Figura 03] de las colecciones del Museo Nacional de Bellas Artes -MNBA-, del cual no existe claridad respecto de su paradero. Generar catalogaciones permite identificar y difundir objetos de valor artístico, cultural y patrimonial, siendo así un valioso instrumento para su conservación.

El corpus de obras de Smith que hemos podido levantar para la propuesta de catalogación se puede dividir analíticamente en una serie de etapas, articuladas por las técnicas y temáticas que en ellas podemos observar. Eugenio Pereira Salas, al referirse al retorno del artista a Santiago, después de su viaje de formación en Europa, señala que a partir de entonces "se abre luego un segundo periodo en su quehacer pictórico, basado en el recuerdo nostálgico de lo que ha vivido en Europa" (Estudios 161). En esta reflexión Pereira Salas desliza la idea que la actividad creativa del pintor estaría dividida en dos periodos, cuyo punto de inflexión sería su retorno a Santiago. A partir de esta idea proponemos catalogar lo obra de Smith en periodos de producción articulados por hitos de su vida, pero tomando en cuenta, además, aspectos artísticos y sus simpatías políticas.

Hemos identificado tres períodos en el desarrollo de la producción de Smith. En el primero se destacan las caricaturas, publicadas en la revista El correo literario ${ }^{1}$. El

1 Cfr.: El correo literario. Año I, desde el No 1 al 5 y 8, 1858. 
segundo período estaría marcado por el obligado viaje que, por problemas políticos, lo lleva a Europa. Situación que enriquece su formación artística. Y, finalmente, el tercer periodo se inicia cuando regresa a Chile para convertirse en el principal protagonista de la consolidación del género de paisaje en la pintura de este país.

Para la catalogación hemos aplicado por una parte, la metodología implementada por Centro de Documentación de Bienes Patrimoniales de la Dirección de Bibliotecas, Archivos y Museos -DIBAM-, formulado en el Manual de Registro y Documentación de Bienes Culturales, editado por Lina Nagel Vega, que recoge experiencias de las instituciones de la DIBAM y de los lineamientos formulados por la Cathegories for the Descripcion of Art, que a su vez son las directrices para la documentación de los bienes desarrollada por Vocabulary Program Getty, la College Art Association of America, y el Cataloging Cultural Objects que plantean estándares de catalogación para documentar objetos culturales (Nagel Vega 4-5).

Si bien existe una serie de estándares establecidos, en esta investigación sólo declaramos aquellos campos de catalogación ${ }^{2}$ para los cuales hemos logrado levantar datos, esto se debe a la informalidad y escasa información disponible respecto de las obras de Smith que están en colecciones privadas. Puntualizamos, además, que la presente propuesta -aclarando que el formato de un artículo no nos permite mostrar íntegramente el catálogo razonado- la describiremos en términos generales, presentando dos obras catalogadas por cada uno de los periodos en que dividimos la producción de Smith.

Por otra parte, también ha sido necesario abordar, tanto un grupo de obras atribuidas a Smith, para hacer el ejercicio de autentificación, como otras que atribuimos al artista. Trabajo que se realizó con el método indiciario establecido por Giovanni Morelli ${ }^{3}$, el cual se centra en un examen de indicios y detalles menos evidentes y trascendentales en la ejecución de una obra, que no se plantea problemas de orden estético, sino previos de orden filológico. Es un método interpretativo que busca la impronta del artista que revela señales involuntariamente generadas, tales como la paleta de matices y tonos usados, en los planos secundarios, el modo de resolver las formas no significativas en la composición: en el caso de Smith, la figura humana, cielo, nubes, montañas, árboles (follaje, tronco, ramas) y la pincelada. Estas características consideramos - siguiendo a Morelli- para analizar la obra como corpus.

2 También conocidos como: estándares, categorías.

3 Para un acercamiento más profundo sobre el método indiciario Cfr.: Ginzburg, Carlo. "Indicios. Raíces de un paradigma de inferencias indiciales". Mitos, emblemas e indicios. Morfología e historia. Barcelona: Gedisa, 1999. 138-175; Quiroga, Samuel y Lorena Villegas. Antonio Smith ¿Historia del paisaje en Chile? Temuco: Ediciones de la Universidad Católica de Temuco, 2014. 


\section{Primer periodo: La caricatura}

Aunque lo más destacable de este período es la caricatura, inicialmente existe un primer acercamiento al retrato - del que conocemos sólo dos trabajos- y aunque hacia el final de su vida lo retoma, no destaca en el conjunto de su obra ni la caracteriza. De su paso por el daguerrotipo (Rodríguez Villegas, Historia 50-1) no hemos encontrado ninguna huella, aunque no descartamos que en el futuro se conozca algo.

El Museo Histórico Nacional - MHN- conserva dos retratos. Uno es un Retrato de Doña Mercedes Trucios y Larrain de Irisarri, fechado en 1848, que en abril de 2006 fue exhibido en la exposición Rostros del pasado, en el MHN. El otro, Retrato de Don Antonio José de Irisarri [Figura 01]. Aunque no tiene fecha, creemos que fue pintado en el mismo año que el anterior, pues ambos retratos comparten características comunes: técnica, soporte, temática. Esta último fue exhibido en septiembre de 1910 en la Exposición del Centenario en el Palacio Urmeneta, en Santiago. Ambas obras pertenecieron a Carmen Smith Canales de Espinoza -hija del pintor-, de quien fueron adquiridas, en diciembre de 1936. Lo más destacable de este periodo es su incursión en la caricatura, género en el cual es pionero, pues son las primeras publicadas en Chile. Vicente Grez nos señala que los primeros intentos artísticos de Smith son las caricaturas que realizaba cuando estudiaba en el Instituto Nacional:

Las inclinaciones del joven eran de las mas alarmantes: manifestaba una repugnancia invencible por el estudio del latín, i cada vez que tomaba en sus manos esta gramática era solo para entretenerse cubriendo sus márgenes con dibujos i caricaturas, en que se burlaba cruelmente de Nebrija y de todos los latinos que el despiadado maestro creó entre nosotros. Estas caricaturas se reproducian infinitamente entre la juventud.

Tan cómicas producciones interpretaban el sentimiento general, i no solo servian para dar a conocer el talento crítico de Smith, sino para crear una atmosfera de admiración i de cariño hacía el espiritual e inspirado paladin, que aparecia atrevidamente resuelto a burlarse de la mas arraigada i venerable preocupacion literaria de la época. El lápiz de Smith se hacia célebre antes que su pincel [sIc.] (Antonio Smith 14-5).

En 1849 Smith ingresa a la recién inaugurada academia, cuyo primer director fue el pintor italiano Alejandro Ciccarelli (1808-1879), donde permaneció por tres años. Al comienzo Smith sorprendió positivamente a Ciccarelli, ganándose su aprecio. El director lo veía como una promesa que le daría gloria a la institución. Sin embargo, con el tiempo Smith manifiesta una muy negativa opinión de la academia; pero su juicio no encuentra apoyo, ni en sus condiscípulos ni en el medio santiaguino. Tal situación lo empuja a romper definitivamente con la entidad y a abandonar el estudio de la pintura. De este paso por la academia sólo hemos encontrado la mención de un 


\section{FIGURA 1}

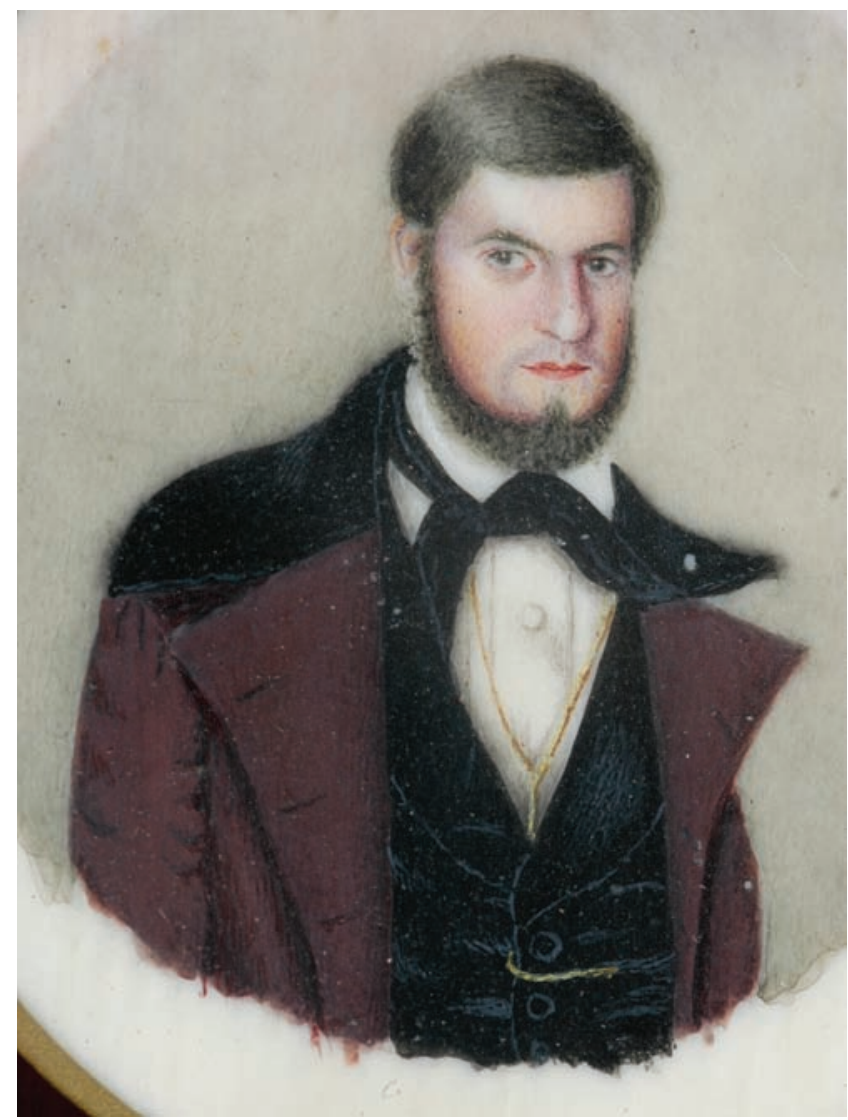

Retrato de Don Antonio José de Irisarri. Antonio Smith. Aguada. Museo Histórico Nacional, Chile.

cuadro sin acabar: Niobe. Pereira Salas nos dice: “[Smith] un día se niega a terminar el cuadro de la Niobe para el concurso, y arrancándose con gesto altivo hacia Peñalolén abandona para siempre los estudios regulares" (150).

Smith, después de abandonar la academia, se instala en Valparaíso, desempeñándose como daguerrotipista (Rodríguez Villegas, Historia de la fotografía 50-1). De esta época no hemos encontrado ningún trabajo. Como tampoco existen rastros de obras realizadas durante el tiempo que vivió en Chillán, seguidamente al dejar Valparaíso. De vuelta a Santiago, consigue un trabajo en la revista El Correo Literario, lo que provoca gran impacto en el medio local, pues esta labor lo encausa hacia la política, involucrándose en el movimiento de oposición al gobierno de Manuel Montt.

El primer número de El Correo Literario aparece el 18 de julio de 1858. En la página 12 se explica que fueron publicadas cinco páginas con ilustraciones: un paisaje -que, por encontrarse incompleto el ejemplar, no se encuentra en el fondo de la Hemeroteca 
de la Biblioteca Nacional en Santiago ni en el archivo que está disponible en el sitio web Memoria chilena- cuya descripción nos hace pensar en un paisaje salido de la pluma de Smith, y cuatro caricaturas. Aunque no se aclara la autoría de las mismas, es posible identificar a los personajes caricaturizados: José Antonio Torres, autorretrato de Antonio Smith [Figura 2], Manuel Blanco Cuartin, y Guillermo Blest Gana: Ilustraciones de este número.

Acompañamos a este número cinco páginas de ilustraciones; una de ellas, es un efecto de luna en el desierto de Atacama tomado desde la bahía de Playabrava, que es el límite de Chile con Bolivia: se ve también en el paisaje la punta de Morro-moreno que es uno de los cerros mas elevados de la costa. A pesar de la aridez de aquel desierto, nada mas poético que un efecto de luna, por lo mismo que solo se presenta a la contemplación, mui en lontananza los estendidos arenales, el mar mansísimo, el elevado Morro-moreno i las lomas de variados colores pero áridos i sin vejetacion alguna. Este conjunto, iluminado por la luna, tiene un aspecto imponente que obra fuertemente sobre la imajinacion. Cuatro caricaturas que representan cada una de ellas una idea i con las que queremos manifestar a los susceptibles, que este jénero nuevo entre nosotros, solo puede inquietar a los lesos [sIC] (Torres 12).

Antonio Smith participó en la revista, con seguridad, hasta el 14 de agosto de 1858 -fecha en que se publicó el quinto número-, pues en el número seis, del 2 de agosto de ese año, pública una nota aclarando su desvinculación de la revista. Las imágenes producidas por Smith publicadas en los números 02 al 05 son:

En el No 2, del 25 de julio de 1858, aparece un retrato titulado El Sr. Jeneral Dn. Francisco A. Pinto, firmado: “A. Smith, 1858", y las caricaturas de Eusebio Lillo, Guillermo Matta, Ángel Custodio Gallo y Juan Domingo Dávila; a lo que se suma la ilustración de un trabajo de Johann Moritz Rugendas.

En el No 3, del 31 de julio de 1858, sólo se encuentra una página con caricaturas, en la que se aprecia a E. del Campo y a Victorino Lastarria. Cabe mencionar que el texto de Eugenio Pereira Salas (160) muestra la reproducción de una caricatura de Diego Barros Arana que pertenecería a este número, pero no nos fue posible encontrarla, ni en el periódico microfilmado en la Hemeroteca de la Biblioteca Nacional ni en el archivo disponible en el sitio web Memoria chilena.

En el No 4, del 7 de agosto de 1858, fueron publicadas cuatro páginas con trabajos de Smith: tres con caricaturas, y otra con ilustraciones publicitarias. La primera está dedicada a Juan Herrera; luego se observan en una misma página dos caricaturas: la de un político que no hemos logrado identificar y la de los hermanos Miguel y Gregorio Víctor Amunategui; en otra página vemos una caricatura dividida en tres cuadros que representan a una mujer vistiéndose para salir a la calle; finalmente, en cuanto a las imágenes que aparecen en la cuarta página, nos parece, no se trataría de caricaturas sino de dos ilustraciones, probablemente de carácter publicitario. 
FIGURA 2

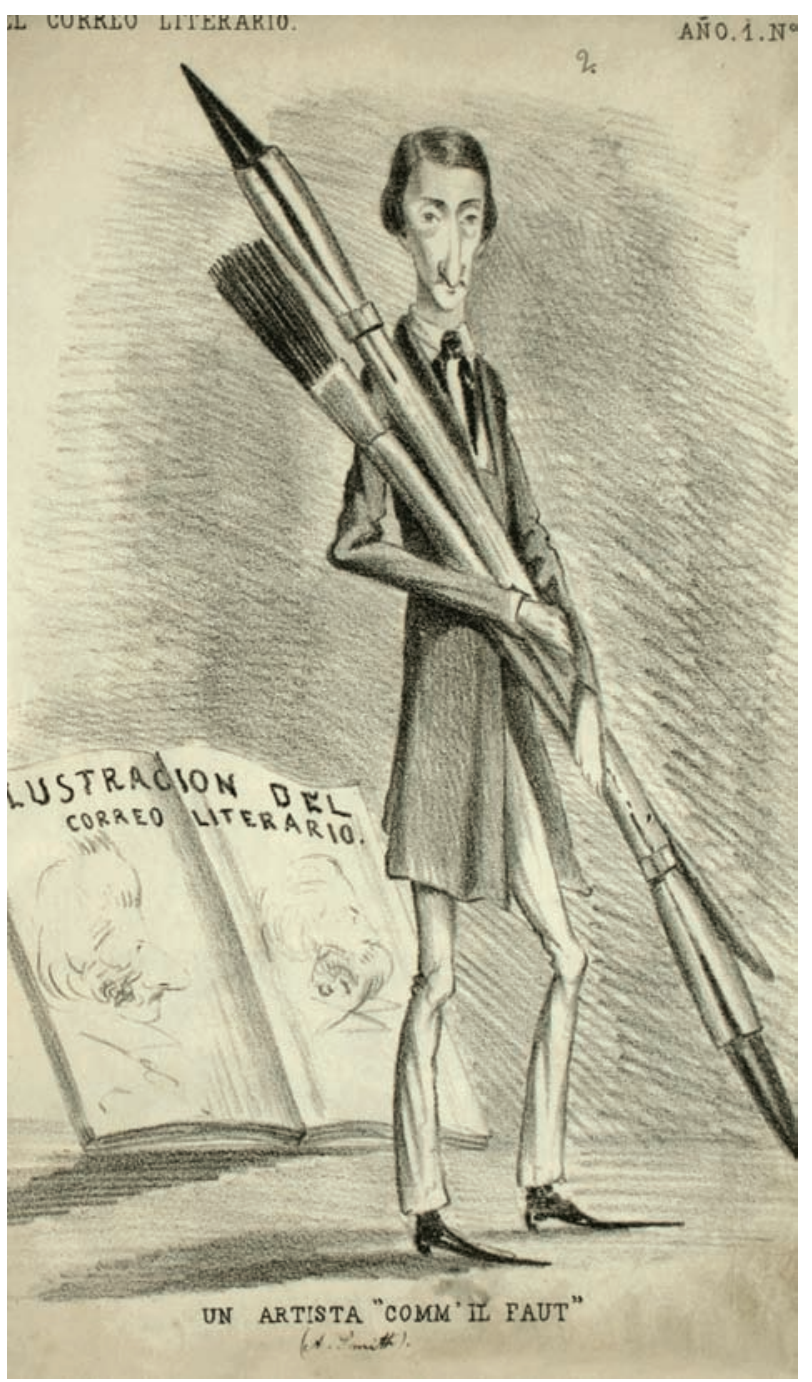

Un Artista "Comn il Faut". Antonio Smith. Lápiz. Biblioteca Nacional de Chile, Chile.

En el No 5, del 14 de agosto de 1858, se publican tres páginas con caricaturas. En la primera vemos la de Francisco Marín y la de un diputado de la época -del que ignoramos su nombre-; en la segunda página se aprecia la caricatura El Quijote; y en la tercera se observan dos: una titulada Ilustración del "Trovador" de Verdi (No 1), y otra donde se representa una balanza, en cuyos recipientes vemos cómo un ejemplar de la revista Del Pacífico se inclina en contra del otro recipiente que está colmado de ejemplares de la revista El Correo Literario. 
En el No 6, del 2 de agosto de 1858, ya no se observa el trabajo de Smith, puesto que, como dijimos anteriormente, se encontraba separado de la revista. A partir de ese momento es Benito Basterrica (1835-1889) quien continúa con la labor gráfica del periódico. Cabe destacar que este número comienza con un artículo escrito por José Antonio Torres, donde se hace una defensa del nuevo género que aparecía en el país: la caricatura ${ }^{4}$. Sin embargo, no se pronuncia, como tampoco lo hará en los números posteriores, respecto de las razones de la salida de Smith y del ingreso de Basterrica a la revista.

En el No 8, del 4 de septiembre de 1858, vuelve a aparecer una caricatura de Smith, esta vez es Alejandro Ciccarelli el personaje representado. Descartamos que haya sido realizada por Basterrica, puesto que de este no tenemos información de discrepancias, oposiciones o críticas con el que era entonces director de la academia. Por el contrario, sabemos que Basterrica lo defendió de los ataques de Ernest Charton, y que fue copista de sus obras:

Benito Basterrica (1835-1889). Alumno de Alejandro Ciccarelli en la Academia, tipógrafo de profesión, espíritu abierto, amplio y liberal, empleó la caricatura como un arte de protesta para expresar el sentimiento social que lo embargaba. Probó la nobleza de su ánimo al defender a su maestro Ciccarelli de los ataques de Ernest Charton, y fiel a sus principios abrió una Academia particular que tuvo que cerrar pronto afligido por la situación económica. Su pintura, en su mayor parte religiosa, le valió recompensas en la Exposición de 1875. Fue muy admirada su Santa Teresa, pintada para la Casa de María. Fino copista de su maestro Ciccarelli y del popular cuadro de Los Últimos Días de Carrera, del uruguayo Blanes (Pereira Salas, Estudios 135).

Tal postura de Basterrica nos inclina a descartar que él haya realizado esta caricatura y a atribuirla a Smith. La historia del arte ya ha documentado ampliamente el antagonismo Smith-Ciccarelli ${ }^{5}$.

$4 \quad$ El agitado y conflictivo ambiente político de 1858, generado por las disputas entre conservadores representados por el Gobierno de Manuel Montt y la oposición liberal, propicia en Chile la aparición de la caricatura, que circula a través de la prensa escrita. De las filas liberales destaca la figura de Smith, quien con sus caricaturas en clave irónica y sarcástica presenta a la clase política y social de entonces. Cfr.: Zaldívar Peralta, Trinidad. "El combate de los lápices. Crisis y caricatura en el siglo XIX. La sátira gráfica puesta al servicio de la lucha política" Arte y crisis en Iberoamérica. Segundas jornadas de historia del arte. Comps. Fernando Guzmán, Gloria Cortés y Juan Manuel Martínez. Santiago: Ril, 2004. 229-245; "Sonrisas de la memoria. Caricatura en Chile: una fuente para el estudio de la iconografía y la identidad nacional" Iconografía, identidad nacional y cambio de siglo (XIX-XX): Jornadas de Historia del Arte en Chile Comps. Fernando Guzmán, Gloria Cortés y Juan Manuel Martínez. Santiago: Rill, 2003, 195-208. "Entre tinta y plumas" Historia de la prensa chilena del siglo XIX. Ed. Ángel Soto. Santiago: Centro de Investigación de Medios Andes (CIMA), Facultad de Comunicaciones de la Universidad de Los Andes, 2004; Montealegre, Jorge. Historia del humor gráfico en Chile. Santiago: Milenio, 2008; Villegas, Lorena y Samuel Quiroga. "La caricatura de Antonio Smith: análisis de obras y revisión historiográfica" La Transitividad de las Imágenes América Latina: Medios, Prácticas, Usos de la Imagen. VI Encuentro de Historiadores del Arte en Chile. Guadalupe Álvarez de Araya (Coordinadora). Departamento de Teoría de las Artes de la Facultad Artes de la Universidad de Chile: Santiago, 2013. Y en Quiroga, Samuel y Lorena Villegas, Op. Cit.

5 Cfr.: Galaz, Gaspar y Milan Ivelic. La pintura en Chile. Desde la Colonia hasta 1981. Valparaíso: Ediciones Universitarias 
En 1859, los conflictos políticos de la revolución provocan la salida de Smith del país. Probablemente, viajar a Europa con el fin de continuar sus estudios de artes era un deseo que tenía desde hacía mucho. Este viaje marca el cierre de una etapa caracterizada por la búsqueda y la experimentación en diversos temas y técnicas.

\section{Segundo periodo: Viaje a Europa}

Para los estados americanos postcoloniales del siglo XIX, Europa era el centro del arte occidental; todo artista que quisiera perfeccionarse debía ingresar en alguna de sus academias. Por tal razón, fueron numerosos los que viajaron con el propósito de continuar su formación. Estos artistas, ávidos de empaparse del arte europeo, recorrían los museos en busca de cuadros y esculturas originales de los grandes maestros para copiarlos. De esta forma iban adquiriendo la técnica y el oficio. Y por supuesto que, además, eran asiduos visitantes de las exposiciones montadas por los salones oficiales, donde podían conocer las obras respaldadas por la crítica, al jurado y al público que las frecuentaba. En la mayoría de los casos Francia, Inglaterra e Italia eran los países escogidos para realizar este peregrinaje ya que, si bien seguían respetando la ejecución técnica tradicional, habían logrado flexibilizar las rígidas ideas que se tenía respecto del arte. Gombrich señala que la ruptura con la tradición se remonta al siglo XVIII. En efecto, el campo de las artes visuales presenta una tensión: por un lado, artistas como William Hogart (1697-1764) (Gombrich 462-464), insatisfechos con la tradición académica se propusieron crear un nuevo tipo de arte para un público nuevo. Por otro lado, artistas como Joshua Reynolds (1723-1792) lucharon por mantener la tradición, puesto que con esta la pintura había dejado de ser una profesión cualquiera cuyos conocimientos se transmitían de maestro a discípulos, ocupando la academia el rol formador al impulsar el "estudio diligente de las obras maestras del pasado y a que asimilaran su técnica. [...] el mismo énfasis puesto en la grandeza de los maestros del pasado, favorecido por las academias, inclinó a los compradores a adquirir obras de los pintores antiguos más que encargarlas a los de su propio tiempo" (Gombrich 480-1).

El efecto inmediato fue que las academias comienzan a organizar exposiciones de las obras de sus miembros, las que se constituyeron en acontecimientos sociales que influían en las reputaciones de los artistas, impactando en las producciones visuales puesto que algunos optaron, para triunfar, por propuestas articuladas desde lo espectacular y pretencioso, desenfocadas de elaboraciones centradas en aspectos artísticos propiamente tales, provocando resistencias de un sector al arte oficial de las academias. Las tensiones aludidas del campo visual generaron una crisis, uno de sus

de Valparaíso, 1981; Cruz de Amenábar, Isabel. Arte en chile. Historia de la pintura y de la escultura de la Colonia al siglo XX. Santiago: Antártica, 1984; Bindis Fuller, Ricardo. Pintura chilena 200 años. Santiago: Origo, 2006. 
efectos fue que los artistas optaran por temas alternativos a los tradicionales (religiosos, mitológicos, alegóricos), lo que llevó a un cambio durante el periodo de la Revolución francesa. En efecto, los artistas se sintieron con la libertad para elegir como tema lo que provocara su interés, desdeñando los tradicionales, lo que fue común entre los creadores consagrados y los rebeldes marginados. Estas nuevas búsquedas fueron, en parte, realizadas por la presencia en Europa, desde América (Gombrich 481-2), de un contingente significativo de pintores y escultores. Uno de los temas nuevos que se perfilaron con más fuerza en este contexto fue el paisaje ${ }^{6}$.

Un gran promotor del surgimiento y desarrollo de estas innovaciones fue el movimiento romántico. Con una nueva visión del mundo, esta naciente sensibilidad enarbola la idea que la obra de arte es la interpretación personal e individual de los sentimientos del alma colectiva. Un cambio trascendental fue el abandono de la jerarquía temática; ahora todo se podía pintar. En el aspecto técnico, el color adquiere gran importancia como medio de expresión y exaltación de los sentimientos. Los artistas ya no se sentían sometidos al predominio del dibujo sobre el color, como ocurría durante el clasicismo. Otro elemento, también fundamental, fue la exposición del paisajismo inglés que se realizó en París en 1824 que, con una larga tradición, mostrándose válido por sí mismo y lleno de intimidad conmueve el ambiente artístico. Este es el panorama con el que se encuentran los artistas chilenos cuando, entusiastas y movidos por un prejuicio estético, ingresan a las academias europeas (Galaz e Ivelic, La pintura 97).

Smith, que habría salido de Chile entre los años 1859 y $1861^{7}$, se instaló en París gracias a la ayuda de Demetrio O’Higgins y Federico Puga. Y al igual que la mayoría de los pintores chilenos que llegaban a Europa, recorrió distintas ciudades visitando sus monumentos y museos. En el Louvre, según Grez, pintó un paisaje inspirado en Georg E. Saal (1817-1870): "En el Louvre copió un hermoso paisaje de Saal; pero como no quería pasar por un servil imitador, transformó el asunto del cuadro, que era una puesta de sol, en una noche de luna. Esta extravagancia llamó la atención de los visitantes i el cuadro fue comprado todavía inconcluso i pagado como un buen original [sIC]" (62).

Según testimonio de Onofre Jarpa (Grez, Antonio Smith s/n), interpretó una obra de Saal al pintar Sol de tarde en la montaña [Figura 3], que pertenece a la colección de MNBA, pero que según registros de dicho museo, en el Oficio No: 99903 del 17 de diciembre de 1973, de la Contraloría General de la República, está en calidad de

6 Para un acercamiento más profundo en torno al surgimiento del género del paisaje ver: Gombrich, Ernst. "La teoría del arte renacentista y el nacimiento del paisajismo" Norma y forma. Madrid: Alianza, 1984. 227-248; López Silvestre, Federico. "Por una historia comprensiva de la idea de paisaje. Apuntes de teoría de la historia del paisaje." Quintana (2003): 287-303; Malosetti Costa, Laura. “¿Un paisaje abstracto? Transformaciones en la percepción y representación visual del desierto argentino" Resonancias románticas. Ensayos sobre historia de la cultura argentina (1820-1890)Eds. Graciela Batticuore y Klaus Gallo y Jorge Myers. Buenos Aires: EUDEBA, 2005. 291-303; Malosetti Costa, Laura. Pampa, ciudad y suburbio. Buenos Aires: Fundación OSDE, 2007. Quiroga, Samuel y Lorena Villegas, Op. Cit.

7 No hay consenso sobre el particular en la literatura consultada, Cfr.: Quiroga, Samuel y Lorena Villegas, Op. Cit. 120-3. 
FIGURA 3

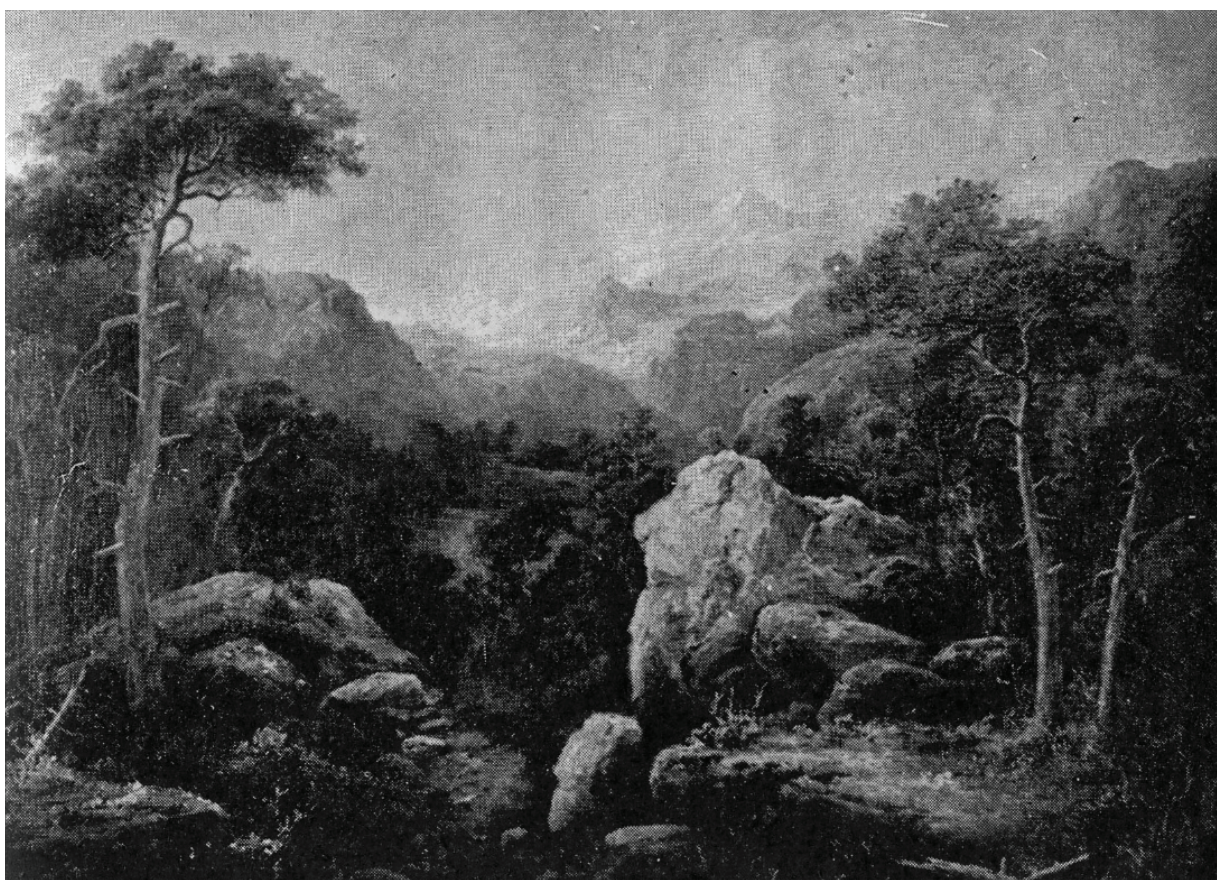

Sol de tarde. Antonio Smith. Óleo sobre tela, 53 x $40 \mathrm{~cm}$. Museo Nacional de Bellas Artes, Chile.

"faltante". Por lo tanto, como no hemos podido encontrarla, optamos por reproducir una imagen en blanco y negro publicada en la segunda edición del libro de Vicente Grez Antonio Smith. (Historia del paisaje chileno), del año 1955, donde a pie de imagen se lee lo siguiente: "Sol de tarde", 0,53 x 0,40 m., óleo de Smith, propiedad del Museo Nacional de Bellas Artes, de la colección Álvarez Urquieta” (s/n).

La escasa información disponible respecto de las obras que pertenecen a colecciones privadas nos impiden por ahora entregar datos de trabajos realizados por Smith en su estadía en Europa. Valdés en las jornadas de historia del arte en Valparaíso en 2010 (222-244), mostró un cuadro, mencionando que lo encontró en Wikipedia al revisarlo, observamos una nota al pie de la imagen que remitía a otro sitio: Latin American $\mathrm{Art}^{9}$. En este hay dos reproducciones de pinturas de Smith, una es la señalada por Valdés: un óleo sobre tela fechado en 1864, de 80 x 99,7 cms., titulado Crepúsculo marino [Figura 4]; la otra es una variante de la anterior; coinciden los títulos, el soporte y la técnica, de $80.3 \times 100,3 \mathrm{cms}$., pero con toda seguridad fue realizada ya de regreso en Chile, a juzgar por la fecha: 1869.

8 Cfr.: es.wikipedia.org/wiki/Antonio_Smith

9 Cfr.: www.latinamericanart.com/es/obras-de-arte/antonio-smith-crepusculo-marino-1. 


\section{FIGURA 4}

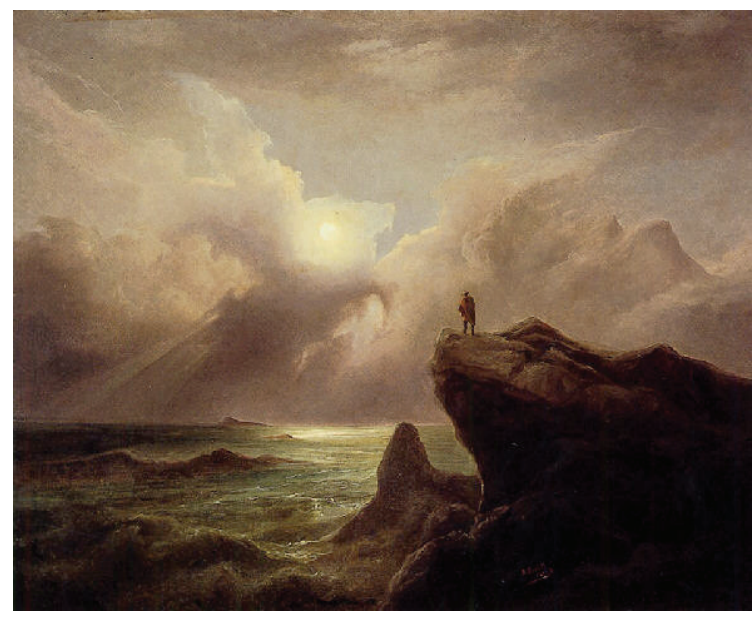

Crepúsculo marino. Antonio Smith. Pintura al óleo. Colección privada, Chile.

En Florencia, Smith se instala por un año, para asistir al taller del paisajista Carlos Markó (1822-1891) (Valdés 238). Aunque, según Vicente Grez, Smith no se habría dejado arrastrar por aquel, pues se cuidó siempre de conservar su carácter y originalidad (63). La escasa información disponible respecto de las obras que pertenecen a colecciones privadas nos impide por ahora entregar datos de cuadros realizados por Smith en su estadía en Europa. Queda pendiente por ahora la catalogación de un número no despreciable de obras, como por ejemplo El Valle de Santiago y las catorce telas que Catalina Valdés señala que presentó al concurso de pintura de la Universidad de Chile en 1969 (237), que pertenecen a este período.

\section{Tercer periodo: El paisaje}

La obra de Manuel Ramírez Rosales (1804-1877) y, principalmente, la de Smith son el inicio de una visión de la pintura chilena que persiste como una tradición que domina la plástica nacional. Smith fue un artista visionario que en la búsqueda de un arte personal rompe con los modelos académicos e introduce en el país, en oposición a la pintura de género clásico, el estilo romántico europeo.

En este sentido, que Smith haya completado en Europa su interrumpida formación artística de Santiago con actividades como el habitual recorrido por museos que los artistas americanos realizaban -en su caso su paso por el Louvre- en busca de obras originales de los grandes maestros para copiarlos, como sabemos que lo hizo con la obra de Saal, fue una de las instancias que conocemos en las que perfeccionó su técnica y oficio; así también fue fundamental su paso por espacio de un año el taller del paisajista Carlos Markó en Florencia. Estas fueron instancias en las que reafirmó 
sus críticas a la rigidez con que Alejandro Cicarelli dirigía la enseñanza artística en Santiago, en especial a la jerarquía temática en la que, por ejemplo, el paisaje era un género instrumental para la pintura de historia. El mejor ejemplo del abandono de la jerarquía temática tradicional es su dedicación exclusiva a la pintura de paisaje, que pinta de un modo completamente novedoso, en tanto que el dibujo ya no es el articulador exclusivo en la construcción de sus imágenes, sino que se complementa junto al color, el cual deja de estar subordinado al anterior como era habitual en la enseñanza académica local, produciendo imágenes más expresivas.

Cuando se observan la obras producidas por Smith luego de su regreso a Santiago, queda claro que no persigue copiar fielmente la realidad sino que prefiere, valiéndose de la naturaleza, el registro subjetivo de aquello que le es útil en la expresión de su estado anímico. Llegó a tal grado su pasión por el paisaje que, abriendo un taller que se especializó en su enseñanza, se convirtió en el gran impulsor de este género en el país, al punto que desde entonces se convirtió en una práctica que paulatinamente llegó a ser tradición en la pintura chilena. A tal grado resulta atractiva esta nueva propuesta, que no son pocos los pintores que se integran a su taller. Allí Smith junto con compartir sus conocimientos promueve la valoración de la naturaleza como fuente de inspiración.

Smith, además, sale de su taller para trabajar al aire libre. Recorre los alrededores de Santiago tomando apuntes para producir la mayoría de sus pinturas, aunque también realizó varios viajes al norte y al sur de Chile. Su método consistía en realizar bocetos que más tarde, en su taller, traspasaba a la tela. Sin embargo hay quienes comentan que algunas de sus pinturas eran simples imitaciones de grabados europeos, que coloreaba según sus fantasías y recuerdos (Cousiño Talavera, Museo 73). La obra de Smith, agrega Grez, es más el producto de un espíritu apasionado y sentimental que de una férrea disciplina de trabajo:

La laboriosidad i el estudio no fue jamás una virtud en Smith, que como se sabe sólo trabajaba cuando estaba de buen humor o cuando las necesidades de la vida lo urjian demasiado [...] Si la composición era sencilla i de pequeñas proporciones, el trabajo no pasaba de tres o cuatro horas, pues su pincel aprovechaba sólo del instante en que vibraba en su alma la emoción poética. En sus más grandes paisajes jamás empleó más de ocho días. Fue ese el tiempo que demoró en pintar el espléndido cuadro Puesta de sol en Los Andes, que obtuvo el primer premio en la esposición de 1875. Esta rapidez en la ejecución esplica la naturaleza de su arte, que no era el resultado del estudio profundo sino de las inspiraciones de su propio ser [...] A sus más bellas composiciones les faltan las últimas pinceladas maestras; rara es su obra completa [sIc] (71-3).

Aunque, según Grez, la disciplina no haya sido el eje de la producción de Smith, y aun siendo cierto lo que señala Luis Cousiño Talavera, su obra tiene un peso y una influencia innegable en la plástica local. Además es importante considerar que fueron 
muchos los que atraídos por su carácter vehemente y sus dotes de líder se aglutinaron a su alrededor. Luis Orrego describe a este personaje rebelde y fascinante del siguiente modo: "Venía a romper los moldes consagrados en la vida santiaguina, con su estilo de bohemio, pero a traer, al mismo tiempo, la nota deliciosa, y nueva del genuino arte nacional, hondo, poético, sentido, vibrante de imaginación, todo idealismo y ensueños que contrastaban con los rudos y a veces groseros materialismos de una sociedad naciente" (“Antonio Smith” 17).

Según Grez, Smith mantiene una intensa actividad artística en los últimos diez años de su vida. Esto es a partir de la apertura de su taller en Santiago:

De 1868 a 1876 fue la época de la gran popularidad de Smith: vendía todos sus cuadros al precio que él les señalaba; [...] Los aficionados se disputaban los cuadros de Smith; todos querían poseer un trozo de nuestra hermosa naturaleza tan poéticamente reproducida. Esos cielos transparentes, esos bosques tan tristes, esas noches de luna llenas de poesía i de amor, encantaban a la juventud. Era ella también la que compraba con preferencia sus cuadros, como que era la que comprendía mejor el alma del artista [sic] (74-5).

En este periodo realiza el mayor aporte al quehacer artístico santiaguino: instala su taller, produce una gran cantidad de obras y contribuye a la formación de un importante grupo de artistas que marcarán la historia de la pintura chilena. Además, en esta etapa participa y triunfa en los concursos de 1867, 1867, 1872 y 1875 . Realidad que confirma el éxito de la pintura romántica y del género del paisaje que impulsa Smith.

En 1867, en la Exposición de Pinturas de la Sociedad de Instrucción Primaria, Smith, que había presentado catorce cuadros - la mayoría realizados en Europa-, ganó el Primer Premio de Paisaje del concurso -adjudicándose \$250- con el cuadro Puesta de sol en las Cordilleras de Peñalolén. Actualmente se desconoce el paradero de esta pintura, sin embargo, Catalina Valdés (222-244) durante las Jornadas de Historia del Arte en Valparaíso, en agosto de 2012, propuso que era bastante probable que fuera la que se reproduce en el libro Pintura chilena del siglo XIX. Alberto Valenzuela Llanos. Visión entrañable del mundo rural, de Origo Ediciones. A partir de las descripciones del cuadro que hacen Ambrosio Letelier (19-21) y Benjamín Vicuña Mackenna (437), ella especula que hablan de la misma pintura con la que Smith ganó aquel concurso. Lamentablemente hasta ahora no ha podido dar con el paradero de la obra, por lo que sólo ha trabajado con reproducciones.

El 16 de septiembre de 1869, en la Universidad de Chile, la Sociedad Artística organiza una exposición en la que, según Arturo Blanco (167), se exhiben los siguientes cuadros de Antonio Smith: Puesta de sol en los Alpes, Sol poniente, Tarde oriental, Salida del sol en el mar, Paisaje de invierno y mediodía. De estas obras no se ha logrado levantar imágenes ni mayores antecedentes. Según Catalina Valdés "presentó catorce telas [...] buena parte del conjunto correspondía a su producción europea” (237). 
El 15 de septiembre de 1872, durante el Gobierno de Federico Errázuriz Zañartu, se inaugura en Santiago el Mercado Central que estuvo a cargo del arquitecto Fermín Vivaceta (1827-1890). Con motivo de su inauguración Benjamín Vicuña Mackenna -intendente de la época- organizó la Primera Exposición de Artes e Industrias, en la que Smith presento varios cuadros. Esta vez obtuvo la Segunda Medalla por la pintura Claro de luna. Posteriormente, en 1906, esta fue adquirida por el MNBA, en el remate de las obras de arte de la Sucesión de Juan Antonio González, por mil novecientos noventa pesos (Cousiño Talavera 80). Más tarde, en septiembre de 1910, fue exhibida en la Exposición Internacional de Bellas Artes que organizó el MNBA con motivo del primer centenario de Chile.

En 1875 el gobierno de Federico Errázuriz Zañartu organiza un concurso de pintura, donde Smith gana la Primera Medalla por Puesta de sol en Los Andes, una de las cuatro pinturas con las que participó. Las otras fueron El día, El crepúsculo y La noche (Sabella 5), de las que desconocemos el paradero. A propósito de esta premiación, Benjamín Vicuña Mackenna, crítico del rol de Estado respecto de la situación de los artistas, escribía lo siguiente: "Entre los veinte premios adjudicados al arte en 1875 (dos primeros, doce de segunda y tercera clase y seis de escultura) otorgáronse, en efecto, a Caro y a Smith los dos premios llamados especialmente de 500 i 250 pesos, que siquiera saldaron el costo de la tela, de los colores, de los marcos y de los desengaños [sIC]" (437). Y más adelante, en el mismo texto, vuelve a insistir en la misma idea:

Fue por esto para nosotros la faz mas brillante de la esposicion de 1875, por que fué la mas práctica y eficaz, el premio especial en plata (que así prosaicamente se llamó) ofrecido a Caro y a Smith como recompensa de sus preciosas telas; y aun que aquella fué solo una suma casi mísera (750 pesos para repartirlos en dos talleres), costearon siquiera con ella los favorecidos el flete del ferrocarril, el carreton en la estación central y las espaldas de los cargadores, para llevar sus armas y sus trofeos alpalenque [sic] (444).

En septiembre de 1910 el MNBA organizó la Exposición Internacional de Bellas Artes, para celebrar el primer centenario de la independencia de Chile. Entre las numerosas obras exhibidas, tres eran de Smith: Efecto de tarde en la cordillera-de la que no tenemos información-, La Cascada -reproducida sin más datos en el libro de Romera (36) - y Claro de luna, que pertenece al MNBA. A este pertenecen tres obras de Smith: Claro de luna, Rio Cachapoal y Sol de tarde en la montaña. La primera, como ya lo señalamos, fue premiada en 1875 y ha sido exhibida en diferentes exposiciones como, por ejemplo, Chile 100 años Artes Visuales del MNBA en el año 2000 (Museo Nacional de Bellas Artes 16-7). La segunda, Rio Cachapoal, ya era mencionada en 1922 en el catálogo del MNBA, donde se señala que había sido adquirida por la Comisión de Bellas Artes (Cousiño Talavera, Museo 72). Ambas obras, que afortunadamente están en buen estado de conservación, además de ser una valiosa muestra del arte chileno, 
evidencian el altísimo nivel que ha alcanzado la pintura de paisaje en la plástica local. De Sol de tarde en la montaña [Figura 3] ya hemos hecho referencia anteriormente.

Otra obra del pintor de la que tenemos conocimiento es Paisaje; que fue prestada temporalmente por el MNBA al Museo de Bellas Artes de Talca, el 08 de abril de $1930^{10}$ y que, según registros del MNBA, poco tiempo después fue cedida a la colección del Museo de Bellas Artes de Talca, según Decreto N 7440, del 15 de octubre de 1934. En ese entonces el Museo O'Higginiano y de Bellas Artes de Talca-MOBAT- no existía porque fue inaugurado el 20 de agosto de 1964. La pintura por tanto debe formar parte de las colecciones del actual MOBAT, porque a este se legaron las colecciones del ex Museo de Bellas Artes de Talca.

Al solicitar una imagen de Paisaje de Antonio Smith al MOBAT, la respuesta fue que ese museo no posee obras del artista solicitado ${ }^{11}$. ¿Dónde está Paisaje? Sabíamos que el MOBAT en su colección tiene algunos paisajes sin autor conocido, ante lo cual nos plateamos la hipótesis de que tal vez entre esas podía estar Paisaje. Los datos que aseguraban que esa obra había sido trasladada hasta el Museo Bellas Artes de Talca, especificaban como título Paisaje, como técnica óleo sobre tela y como medidas 29 por $36 \mathrm{~cm}^{12}$. Lo que se aproxima a Paisaje. Montaña con nubes, pues coincide con la técnica y se acerca a las medidas $(28 \times 36)$ de este paisaje sin autor conocido que el MOBAT registra en sus colecciones, según los datos que pudimos obtener en el sitio web Sur-DIBAM-. Visitamos el MOBAT, para ver los paisajes sin autor conocido, especialmente Paisaje. Montaña con nubes. Consultamos los registros más antiguos del museo, un inventario de 1974 en el cual no figura el traspaso de Paisaje de Antonio Smith. Sin embargo, en dicho inventario, en la página 6 encontramos un registro de la obra que habíamos visto en Sur, cuyos datos, por su aproximación con la obra que buscábamos, llamaron nuestra atención: "Página $\mathrm{N}^{\circ}$ 6, con el título Pinturas del "Grupo 1", con el número 59 (cincuenta y nueve). Paisaje. Montaña con nubes, tela 36 x 29 ctm. Autor Anónimo" (Museo O’Higginiano y de Bellas Artes de Talca 6).

Es habitual encontrarse con imprecisiones respecto de los títulos de una obra según la fuente consultada. Lo que podría explicar el cambio desde Paisaje a Paisaje. Montaña con nubes. La técnica coincide, las medidas son próximas, cabiendo la posibilidad de que al tomarlas haya habido un proceder distinto en un primer momento, antes de que la obra salga del MNBA en 1930, y las que se han tomado para el registro del inventario de 1974, como las registradas por el Laboratorio de Pintura, del Centro Nacional de Conservación y Restauración (DIBAM) cuando el 21 de enero de 2011 ingresó para su restauración: "Se trata de una pintura de caballete, óleo sobre tela en

10 Esta información consta en el Oficio No 197, disponible en el Fondo DIBAM del Archivo Histórico Nacional.

11 Respuesta vía e-mail, de: Gonzalo Olmedo E., a: Patricia Herrera, esta reenvía a: Samuel Quiroga S., con fecha 10 de septiembre de 2012. Agradecemos a la Magt. Patricia Herrera por habernos coordinado con el investigador y documentador del MOBAT para visitar el museo en Talca. Como también a Claudia Vergara Y., Marianne Wacquez y a Gonzalo Olmedo E. por su amabilidad y colaboración, sin la cual no hubiéramos podido dar con esta obra.

12 Oficio No 197 antes citado. 
pequeño formato, de 28.5 x $36 \mathrm{~cm}$. (sin marco)" (3). Creemos que Paisaje y Paisaje. Montaña con nubes son la misma obra por lo que nos atrevemos a atribuirla a Smith. Lo que sostenemos por los antecedentes antes expuestos y la aplicación del método indiciario de Giovanni Morelli. La atribución, que proponemos de esta pintura a Smith, la levantamos a través de un análisis visual exhaustivo de la obra. Se comparó con algunos cuadros acreditados al autor, que en conjunto forman una serie de la cual esta obra sería parte, entre ellas Montañas ${ }^{13} \mathrm{y}$ Volcán tronador ${ }^{14}$-grupo control-. En la comparación de indicios, en sintonía con el método aludido, se pone el foco en aquellos detalles menos evidentes o trascendentales en la ejecución de una obra. Para ello establecimos parámetros de comparación entre las obras de grupo control y Paisaje. Montañas con nubes identificando un conjunto de indicios que nos revelan estar en presencia de una factura común manifestada en el mismo tratamiento para la configuración de los elementos secundarios de la composición, en este caso específico el tratamiento de árboles, el modo automático de solucionar detalles como follaje y troncos; ese mismo proceder es observable en el modo de configurar las formas rocosas y suelos, la estructura y color utilizado en la manera de representar la cordillera, al igual que la forma de proyectar la luz, así como también las atmosferas producidas. También encontramos indicios comunes con Rio de Cachapoal ${ }^{15}$ tales como la paleta cromática empleada, que es equivalente en matices y tonalidades, al igual que la conformación de las formas anteriormente mencionadas.

Otras cuatro pinturas del maestro se encuentran en La Pinacoteca de la Universidad de Concepción. La primera es Valle cordillerano, firmado y fechado en 1874, y reproducido en Galaz e Ivelic (99). La segunda es Paisaje, ex Colección Tole Peralta. La tercera es Valle de Aconcagua, que en Antonio Romera (Asedio a la pintura chilena $\mathrm{s} / \mathrm{n}$ ) ha sido reproducida con el título de Paisaje. Y la cuarta es Paisaje de cordillera, según Cruz de Amenábar (180), la misma que Galaz e Ivelic (97) llaman Paisaje cordillerano, y también es llamado Paisaje del Aconcagua por Rodríguez (43). Esta última formó parte de la exposición Siglo y medio de pintura chilena (Desde Gil de Castro al presente), organizada por el Instituto Cultural de Las Condes en 1976, según se puede constatar por la imagen en blanco y negro que aparece en el catálogo. Ha sido reproducida, además, en Galaz e Ivelic (97), en Cruz de Amenábar (180) y en prensa (Rodríguez 43). Afortunadamente, todas las obras de Smith pertenecientes a las colecciones de la Pinacoteca de la Universidad de Concepción y la DIBAM están catalogadas según los estándares que esta última ha implementado como anteriormente mencionamos.

También en el MHN encontramos dos cuadros de Smith: Valle de Vitacura y Peñalolén. Ambos fueron legados a este museo por Germán Vergara Donoso el 28

13 Perteneciente a la colección del Club de Viña del Mar

14 Vendida en Casa de Remate Enrique Gigoux a una colección privada.

15 Perteneciente a la colección del Museo Nacional de Bellas Artes, Santiago. 
de enero de 1988. Fueron exhibidas en la exposición Tres siglos de dibujo en Chile. Desde sus inicios hasta nuestros días. Colección Germán Vergara Donoso del Instituto Cultural de las Condes, desde el 19 de octubre hasta el 06 de noviembre de 1988. Peñalolén, además, fue expuesta en la muestra El paisaje chileno. Itinerario de una mirada. Colección de dibujos y estampas del Museo Histórico Nacional, en el año 2011 (Museo Histórico Nacional 190).

En la colección del Banco BBVA de Santiago encontramos Paisaje de cordillera, también llamado Atardecer cordillerano, que fue presentada en la exposición Arte Latinoamericano en la Colección BBVA, montada en el Palacio del Marqués de Salamanca, en Madrid, desde el 21 de septiembre al 18 de diciembre de 2007. También, en el marco de la Trienal de Chile 2009, fue presentada en la exposición, curada por Roberto Amigo en el MNBA, Territorios de Estado. Paisaje y cartografía. Chile, siglo XIX. Y en la exposición Confluencias. Dos siglos de modernidad en la Colección BBVA, presentada entre el 9 de junio y el 15 de agosto de 2010 en el MNBA.

Otras instituciones que conservan obras de Smith son: Casa Museo Eduardo Frei Montalva, que en su colección cuenta con Paisaje; la Embajada de Chile en Washington, donde encontramos una vez más una pintura con el título Paisaje. La colección del Banco Central de Chile tiene tres pinturas atribuidas a Smith: Marina, Valle de Aconcagua y Peñalolén.

En Ricardo Bindis Fuller (Pintura chilena 52) se aprecia Volcanes, sur de Chile, quien, en una entrevista, nos reveló que la obra había pertenecido a la colección de Raúl Peña L., y que este la vendió a un coleccionista privado. En Eugenio Pereira Salas (Estudios 162) se reproduce Montañas, lamentablemente en blanco y negro. Sin embargo, gracias a la gentileza del Club de Viña del Mar que nos permitió fotografiar la obra, hemos podido reproducirla en esta publicación [Figura 5]. En Isabel Cruz de Amenábar (Arte en Chile 178) se puede apreciar Playa de Quintero. En la revista Selecta (20) apareció una reproducción sin más referencia que el título de la obra: Paisaje, de la que tampoco hemos podido recabar más antecedentes. Y en El cronista dominical, del 11 de julio de 1976, fue reproducido en blanco y negro Lago en la montaña con ocasión de la muestra Siglo y medio de pintura chilena que se realizó en el Instituto chileno-norteamericano de cultura. Dos están publicadas en el sitio web de la Casa de Subastas Jorge Carroza López: Nocturno claro de luna -adquirida por el Banco de Chile en 2010 - y Claro de luna en el bosque, vendida a una colección privada. Esta misma casa de subastas, en el año 2012, tenía a la venta otro paisaje sin título del autor. En el sitio web de Remates de Artes y Antigüedades hallamos dos obras: Volcán Tronador [Figura 6] y otra, Sin título, que aparece como vendida a una colección privada. Catalina Valdés, en las jornadas de historia del arte en Valparaíso 2012 mostró la imagen de una obra de Smith que encontró en el sitio Latin American Art en la que se pueden ver las imágenes de dos cuadros de Smith que aparecen con el mismo nombre: Crepúsculo marino. Y en el sitio web de la Policía de Investigaciones de Chile, se señala que de las dependencias de la Casa de Remate Juan Pablo 
FIGURA 5

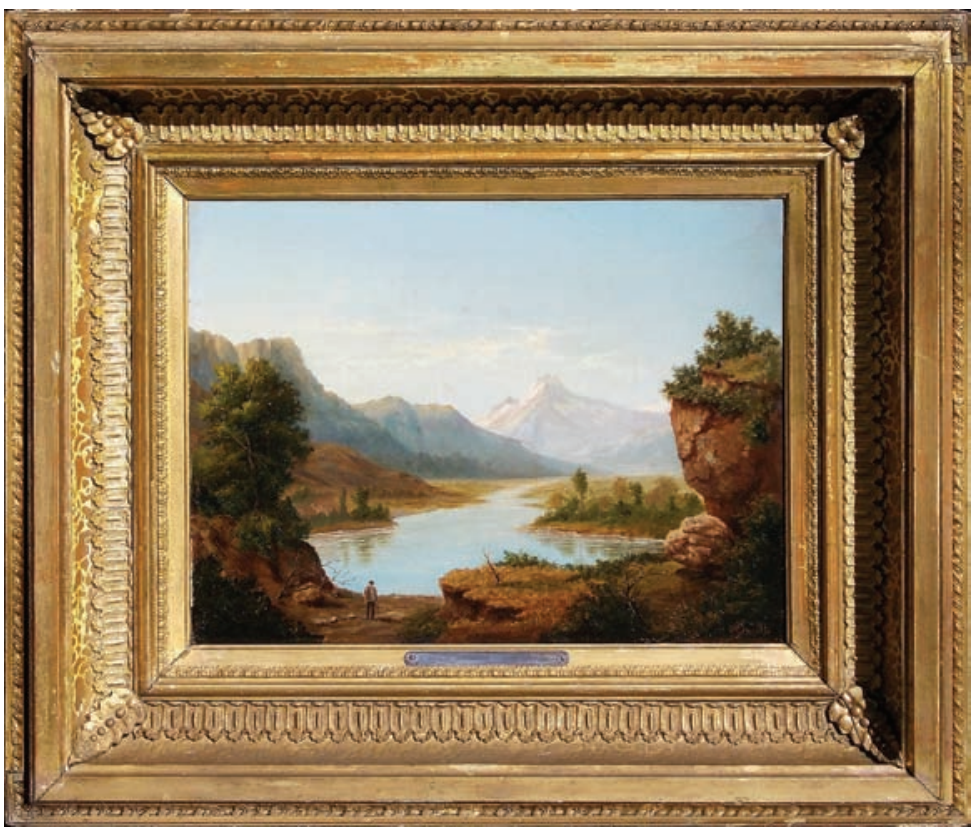

Volcán Tronador. Antonio Smith. Óleo sobre tela, 35.5 x $46 \mathrm{~cm}$. Remate Enrique Gigoux Renard, Chile.

\section{FIGURA 6}

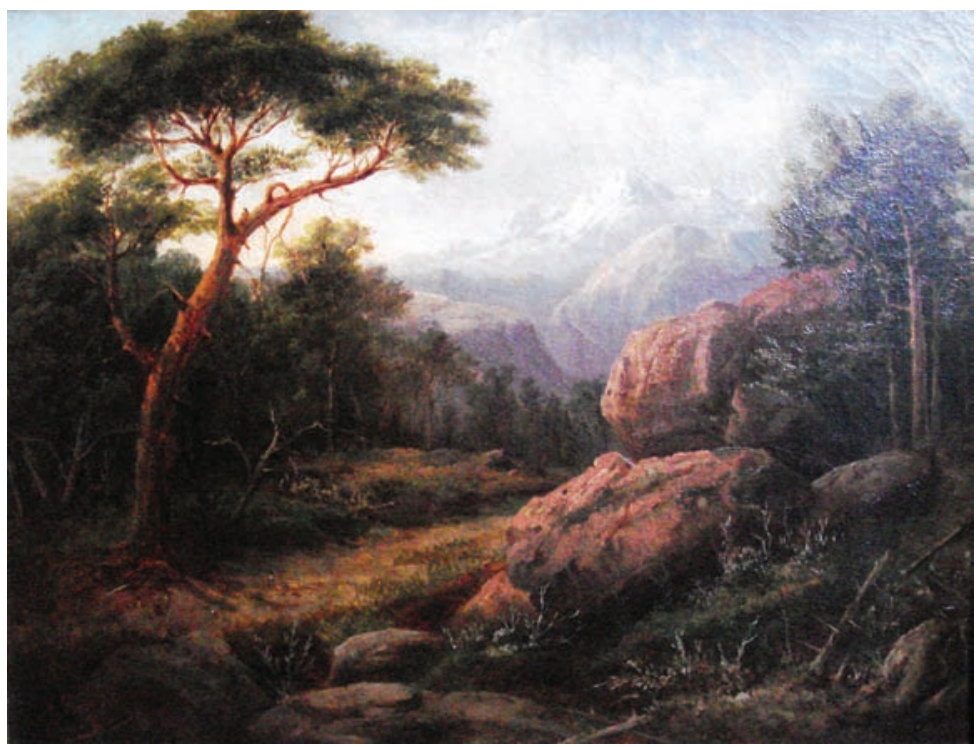

Montañas. Antonio Smith. Óleo sobre tela, 37 x $48 \mathrm{~cm}$. Club de Viña, Chile. 
Montero, ubicada en la comuna de Recoleta, en Santiago, fueron sustraídos dos óleos sobre madera: Amanecer en cordillera y Paisaje. Según se indica, el hecho ocurrió el 22 de enero de 2009.

No podemos dejar de mencionar que de aquellas que Romera señala como las mejores obras de Smith -Puesta de sol en Los Andes, Bosque indígena en noche de luna, Valle de Santiago, Una casada, El lago, Capricho y Las cuatro horas del día- a excepción de Una cascada, no hemos encontrado imágenes, tampoco referencias que den cuenta de su actual ubicación y estado.

La última y más brillante etapa de la producción artística de Smith comienza a declinar junto con su salud. Durante su convalecencia se "aísla en la paz del hogar [...] Pinta algunos retratos, muy ajenos a su estilo, pero de interesante factura como el retrato al óleo de doña Amelia C. de Huidobro" (Pereira Salas, Estudios 165), de la que no hemos podido hallar más información.

\section{Conclusiones}

Hemos logrado identificar tres fases en el desarrollo de la producción artística de Smith: La caricatura, Viaje a Europa y El paisaje, además catalogar 63 obras que sumadas a las 15 ya catalogadas por las instituciones de la DIBAM y la Pinacoteca de la Universidad de Concepción nos permiten dar cuenta en total de 78 obras con datos y reproducción. El primer período: la caricatura, se distingue principalmente por las caricaturas que realizó para la revista El Correo literario, siendo pionero en el género, pues son las primeras que se publican en Chile. De este período de un total de 26 obras, 6 fueron catalogadas por el MHN, y 20 fueron realizadas en esta investigación. Del segundo período: viaje a Europa, si bien sabemos que de este periodo a lo menos hay 15 obras que trajo desde Europa, desconocemos el paradero de ellas. Por lo que sólo damos cuenta de 2 obras catalogadas por esta investigación. Finalmente, del tercer y último periodo: el paisaje, que se inicia cuando regresa a Chile, catalogamos 50 obras en total, 9 registradas por la DIBAM y la Pinacoteca de la Universidad de Concepción, y las 41 restantes sistematizadas en esta investigación.

Realizar esta catalogación ha sido una tarea compleja; la primera dificultad con la que nos encontramos fue la escasa información que existe sobre la producción de este artista. De ahí la importancia de catalogar su obra, pues como hemos constatado, esta se encuentra dispersa -y muy poco registrada- en colecciones privadas. Si bien se la encuentra reproducida en algunos textos, estos abundan en apreciaciones personales y no entregan datos concretos sobre su historial. Además, es común encontrarse con todo tipo de imprecisiones que solo originan confusiones. La falta de información es una amenaza para el patrimonio y su conservación. Por lo mismo se hacía imperioso lograr un registro que diera cuenta de la obra de Smith. Así, hemos identificado con bastante nitidez tres periodos, a modo de una 
propuesta referencial que plantea este orden para facilitar su estudio y valoración. Además, es una base de datos para otras investigaciones, pues aporta información concisa, especializada y actualizada. El resultado de nuestro trabajo ha sido un avance significativo respecto de lo que había; damos cuenta de 78 obras, de las cuales reproducimos 6 en este artículo.

\section{Referencias}

Bindis Fuller, Ricardo. Pintura chilena 200 años. Santiago: Origo, 2006. Medio impreso. Blanco, Arturo. "Antonio Smith, pintor de paisajes y caricaturista chileno". Universidad de Chile. Anales 94 (1954): 164-171. Medio impreso.

Casa de Subastas Jorge Carroza L. www. galeriacarroza.com/lote.asp?id=142. Fecha de ingreso: 03 de enero de 2009. Sitio web.

Cousiño Talavera, Luis. Museo Nacional de Bellas Artes. Catálogo General de las Obras de Pinturas, Esculturas, etc. Santiago: Imprenta y Litografía Universo, 1922. Medio impreso.

Cruz de Amenábar, Isabel. Arte en chile. Historia de la pintura y de la escultura de la Colonia al siglo XX. Santiago: Antártica, 1984. Medio impreso.

DIBAM. Sur. www.surdoc.cl. Fecha de ingreso: 19 de julio de 2009. Sitio web.

El Mercurio. "Banco de Concepción: Destruidas 15 valiosas pinturas chilenas". El Mercurio 14 de enero de 1981.37. Medio impreso.

Galaz, Gaspar y Milan Ivelic. La pintura en Chile. Desde la Colonia hasta 1981. Valparaíso: Ediciones Universitarias de Valparaíso, 1981. Medio impreso.

Gombrich, Ernst. La historia del arte. New York: Phaidon, 1997. Medio impreso.

Grez, Vicente. Antonio Smith (Historia del paisaje en Chile). Santiago: Universidad de Chile, 1955. Medio impreso.

---. Antonio Smith: Historia del paisaje en Chile. Santiago: Establecimiento Tipográfico de la Época, 1882. Medio impreso.

Laboratorio de Pintura. Centro Nacional de Conservación y Restauración. Informe de intervención. Paisaje. Montaña con nubes. Anónimo. Santiago, 2011. Medio impreso.

Latinamericanart. www.latinoamericanart.com/es/obras-de-arte/antonio-smithcrepusculo-marino-1.html. Fecha de ingreso: 16 de agosto de 2012. Sitio web.

Letelier, Ambrosio. Reseña descriptiva de la Esposición Internacional de Chile en 1875 [sIC]. Santiago: Imprenta Franklin, 1875. Medio impreso.

Museo Histórico Nacional. El paisaje chileno. Itinerario de una mirada. Colección de dibujos y estampas del Museo Histórico Nacional. Santiago, 2011. Medio impreso.

Museo Nacional de Bellas Artes. Chile 100 años. Artes Visuales. Santiago, 2000. Medio impreso.

Museo O’Higginiano y de Bellas Artes de Talca. Inventario. Talca, 1974. Manuscrito. 
Nagel Vega, Lina (ed.). Manual de Registro y Documentación de Bienes Culturales. Santiago: DIBAM, 2008. Medio impreso.

Orrego Luco, Luis. “Antonio Smith”. Selecta (abril de 1909): 17-20. Medio impreso.

Pereira Salas, Eugenio. Estudios sobre la Historia del Arte en Chile Republicano. Santiago: Ediciones de la Universidad de Chile, 1992. Medio impreso.

Quiroga, Samuel. “Juan Francisco González Escobar (1853-1933)”. Revista de História da Arte e Arqueología (Jul-Dez 2009): 67-87. Medio impreso.

Quiroga, Samuel y Lorena Villegas. Antonio Smith ¿Historia del paisaje en Chile? Temuco: Ediciones de la Universidad Católica de Temuco, 2014. Medio impreso.

---. "Aspectos de la formación artística y circulación de la obra de Antonio Smith que inciden en la catalogación de su legado". El sistema de las artes. VII Jornadas de Historia del Arte. Eds. Abella, Raquel, et. al. Universidade Federal de São Paulo-Museo Histórico Nacional-Facultad de Artes Liberales de la Universidad Adolfo Ibáñez-Centro de Restauración y Estudios Artísticos CREA: Valparaíso, 2014. Medio impreso.

Remates de Artes y Antigüedades. www. gigox.com/detalle2. asp?all=1\&prodid=267 $8 \&$ catid $=155$. Fecha de ingreso: 02 de enero de 2009. Sitio web.

Rodríguez Villegas, Hernán. Historia de la fotografía. Fotógrafos en Chile durante el siglo XIX. Santiago: Ograma, 2001. Medio impreso.

Rodríguez, Marcelo. “Antonio Smith y la naturaleza romántica”. La Nación (1 de junio de 1986): 43. Medio impreso.

Romera, Antonio. Asedio a la pintura chilena (Desde el Mulato Gil a los bodegones literarios de Luis Durand). Santiago: Nascimento, 1969. Medio impreso.

---. Historia de la pintura chilena. Santiago: Andrés Bello, 1976. Medio impreso.

Sabella, Andrés. "Linterna de papel. Antonio Smith". Las últimas noticias (22 de noviembre de 1975): 5. Medio impreso.

Torres, José Antonio. "Ilustraciones de este número". El Correo Literario (18 de julio de 1858) : 12. Medio impreso.

Valdés Echeñique, Catalina. “Un pintor chileno en el Café Michelangelo. Vínculo ente la Escuela de Staggia y la pintura de paisaje chilena” Eds. Fernando Guzmán y Juan Manuel Martínez. Vínculos artísticos entre Italia y América. Silencio historiográfico. VI Jornadas de Historia del Arte. Santiago, 2012. 222-244. Medio impreso.

Vicuña Mackenna, Benjamín. "El arte nacional. I su estadística ante la Esposición de 1884". Artes y letras 9 (15 de noviembre de 1884): 418-448. Medio impreso.

Villegas, Lorena y Samuel Quiroga. "La caricatura de Antonio Smith: análisis de obras y revisión historiográfica”. La Transitividad de las Imágenes América Latina: Medios, Prácticas, Usos de la Imagen. VI Encuentro de Historiadores del Arte en Chile. Coord. Guadalupe Álvarez de Araya. Departamento de Teoría de las Artes de la Facultad Artes de la Universidad de Chile: Santiago, 2013. Medio impreso. 
Zaldívar Peralta, Trinidad. "El combate de los lápices. Crisis y caricatura en el siglo XIX. La sátira gráfica puesta al servicio de la lucha política”. Arte y crisis en Iberoamérica. Segundas jornadas de historia del arte. Comp. Fernando Guzmán, Gloria Cortés y Juan Manuel Martínez. Santiago: Ril, 2004. 229-245. Medio impreso.

Recibido: 24 abril 2014 Aceptado: 03 septiembre 2015 